\title{
The Impact of COVID-19 on the Efficiency of Packing Lines in Pharmaceutical Manufacturing Sites in Egypt
}

\author{
Ashraf Elsafty $^{1} \&$ Mohamed Osman ${ }^{2}$ \\ ${ }^{1}$ Adjunct Assistant Professor, Eslsca University Egypt, Egypt \\ ${ }^{2}$ MBA Candidate, Eslsca University Egypt, Egypt \\ Correspondence: Ashraf Elsafty, Adjunct Assistant Professor, Eslsca University Egypt, Egypt. E-mail: \\ ashraf.elsafty@eslsca.edu.eg
}

Received: April 28, 2021

Accepted: May 26, 2021

Online Published: June 8, 2021

doi:10.5539/ijbm.v16n7p57

URL: https://doi.org/10.5539/ijbm.v16n7p57

\begin{abstract}
Corona Virus Disease COVID-19 has significantly impacted the pharmaceutical manufacturing sector. Production Efficiency in pharmaceutical facilities is questionable to withstand the drastic conditions under which the drug manufacturing supply chains are. Overall Equipment Effectiveness (OEE) is a primary indicator of efficiency. The aim of this review is to demonstrate a comprehensive overview on the factors impacting OEE and how they are affected by COVID-19.

This review was done on a multinational pharmaceutical manufacturing facility in Egypt. In order to better understand the business model under study and have clearer vision on the impact of COVID-19 on each aspect of it, the business anatomy model ' 9 Elements' by Elsafty (2018) was used. The time horizon of this study is 2020 to understand the impact of the COVID-19 pandemic on the pharmaceutical manufacturing performance.

The pandemic led to increase the pharmaceutical products demand which subsequently put a pressure on supply planners to alter the production scheduling. COVID-19 unraveled the weaknesses in the supply chains and the overreliance on materials suppliers of one source. This had a direct impact on the supply of materials and spare parts. Production efficiency has also been impacted by the health conditions of workers and operators might been community infected. Lack of high-skilled workers leads to decrease in the productivity due to the inability to manage and solve problems the right way and independently. Materials and finished goods quality are questionable in such situation. Introduction of counterfeit and falsified materials is a predictable side effect.
\end{abstract}

It is concluded that OEE is affected by COVID-19 that moderates the inputs of OEE; availability, performance and quality. The pandemic has an impact (positive or negative) on the top losses of a machine efficiency.

Keywords: Overall Equipment Effectiveness (OEE), COVID-19, Pharmaceutical, efficiency

\section{Background and Problem Definition}

Pharmaceutical Industry is a regulated discipline. Ministry of Health of Egypt (MOH) is the main regulatory authority for pharmaceutical products in terms of products' registration, pricing and manufacturing practices through a series of requirements and regulations called; Good Manufacturing Practices (GMP). GMP ensures product quality by regulating the process critical quality attributes. As any other business in Egypt, pharmaceutical industry has been impacted by the economic status of country, which in-turn resulted from the COVID-19 pandemic situation since the World Health Organization declared the outbreak as a global emergency. WHO (2020) stated that coronavirus disease (COVID-19) is an infectious disease caused by a newly discovered coronavirus. Pharmaceutical products are considered critical to national security products.

The time horizon of this study is 2019-2020 to understand the impact of the COVID-19 pandemic on the pharmaceutical manufacturing performance.

To better understand the business model under study and have clearer vision on the impact of COVID-19 on each aspect of it, using the business anatomy model ' 9 Elements' by Elsafty (2018), developed and updated with several applied studies. According to Elsafty (2020) the Nine Elements Framework Model covers and map business anatomy to better identify and define the context under research study, exploring and assessing contextual analysis of research focus, like legal type of researched organization, management level, business 
functions, internal \& External environmental factors, geographical location and industry field we can explore all of these elements within time frame, the model used developing several papers published within business and management research areas (Elsafty, A., Elsayed, \& Shaaban, 2020; Elsafty A., \& AlNawaly, 2020; Elsafty A., \& Ragheb, 2020; Elsafty, A., \& Abadir \& Sharawy, 2020; Elsafty, A., Elbouseery, I., \& Shaarawy, A., 2020; Elsafty, A., \& Tahon, A., 2021; Elsafty, A., \& Elzeftawy, A., 2021).

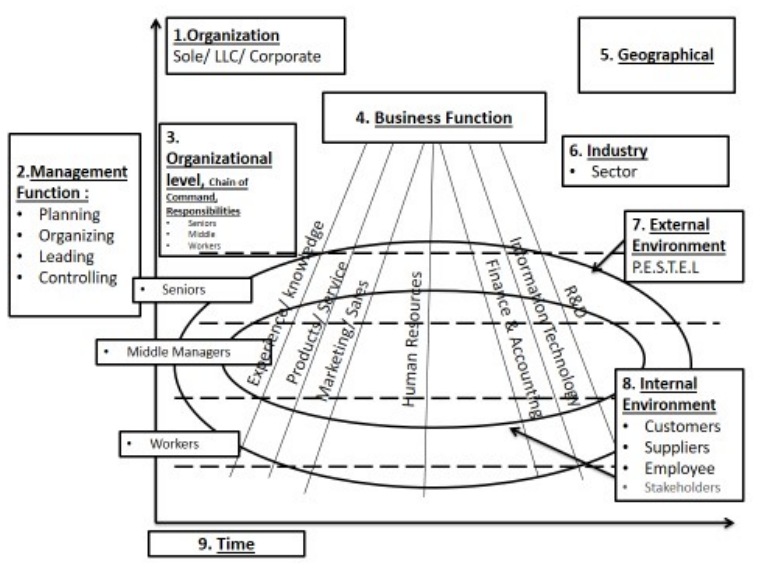

Figure 1. Business anatomy model - 9 elements (Elsafty, 2020)

\subsection{Organization and Management}

The organization under assessment is a large well known, top ranked pharmaceutical corporate. It represents multinational companies that operates in a wide range of regions and countries across the globe. Company's name will not be disclosed due to data privacy and security reasons.

The Supply chain management approach is quite similar in all of pharmaceutical companies in Egypt. Demand driven planning model is commonly used. Production plans are developed based on forecasted demand for each product and Stock Keeping Unit (SKU). Prior to the production process which is the scope of this study, planning and alignment process is being done to verify availability of resources and applicability to meet the demand. Each year an estimated sales forecast is submitted by marketing and demand planning teams. Which is then reviewed on monthly bases to capture any positive or negative trends and changes in the originally submitted plans. A regular standard meeting called S\&OP (Sales and Operations) is held with all relevant stakeholders from operations, sales, marketing, distribution and demand planning teams. The meeting is governed by top management and the minutes of the meeting and recommended actions are captured and agreed upon. Once estimated sales forecast (ESF) is reviewed, planning teams in the manufacturing facility start materials requirements planning to ensure availability of the active pharmaceutical ingredients, excipients, and packaging components at the time of production. Then production plan is set to meet the demand requirements on time. Service level agreement is in place defining the responsibilities and cycle time for each step. That acts as the standard against which the performance of each function is assessed. Production team is responsible for the execution of the production plan.

According to Nicola (2020) COVID-19 outbreak had a profound impact on pharmaceutical sector. On one hand, production slow-downs and limitations in supply would lead to revenue loss. Supply chain deficiency and postponement of all improvement plans to direct resources on securing supply of critical products will affect revenue growth in 2020. Massive transformation in supply model and supply chain design is likely to be planned for in response to the pandemic that revealed gaps and addressed risks of supply chain weak points.

On the other hand, opportunities have emerged for any company engaged in vaccine and drug development or having plans for development of a cure or a vaccine. Clinical trials are being conducted to evaluate an investigational COVID-19 vaccine. Nonetheless, demand has significantly increased for products that are related to the treatment of COVID-19 and its related symptoms or implications. As the case for Dexamethasone demand that has ramped up upon publication of the preprint of a study called RECOVERY held at Oxford University as mentioned in an article on BMJ (Mahase, 2020).

A periodic governance and review process is in place to monitor the performance in all five business aspects Safety, Quality, Supply, Cost and People to address any adverse trend or performance decline to take the proper 
remedial actions. Standard set of Key Performance Indicators (KPIs) monitors and controls the performance of the operations process. These KPIs are totally aligned with the companies' values, strategies and priorities. Under different names, same metric with standard calculations are used in all the companies studied.

Productivity and efficiency are measured by specific set of KPIs such as OEE, productivity, MTBS, MTTR, MTBF...etc. Customer service, On-time/In-full (OTIF) and forecast accuracy are among the metrics that measures the supply chain performance.

In a study done on 506 KPIs of pharmaceutical industry, OEE was considered one of the influential metrics on shop floor level. It includes analysis and reporting that paves the way for productivity improvement and waste elimination (Annabi, Kebriaeezadeh, Shoshtari, \& Ghodsi, 2015).

In order to better examine the impact of COVID-19 on pharmaceutical production facilities efficiency, OEE is the metric indicator of choice to assess the impact on the equipment efficiency factors. According to Sowmya and Chetan (2016) OEE is proved to be an efficient metric tool to drive improvement as it is the simplest way to calculate effective utilization of machines. OEE represents the percentage of time the machine is in production of the total time it is supposed to be producing good quality product. OEE is the outcome of combining three metrics; Availability, Performance and Quality.

A simple glance at the below graph for OEE\% per week in 2020 for a packing line, it is noticeable that there is high variability during the period from week 20 to week 37 .

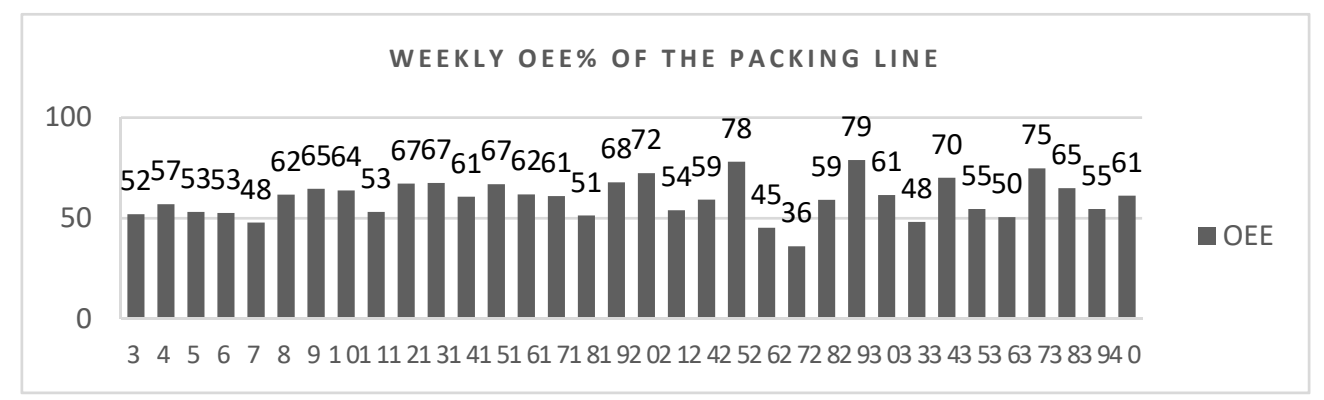

Figure 2. Weekly OEE of the packing line

About the management function, strategies is deployed top-down from strategic company goals to regional plans to sites objectives. Goals cascading is done in a way that ensures site level plans and objectives are aligned with the regional plans and is derived from the global objectives. A flat organization structure is adopted with span of control range from 1 to 22 in all the companies selected.

\subsection{Industry and Business Function}

The core business of these firms is pharmaceutical manufacturing. The study focuses specifically on oral dosage forms packaging in the Egyptian market. The organization structure of the site is presented in the chart (Figure 2) showing the different departments such as; Process Execution Team - PET - Lead or Value Stream Lead, Quality, Safety, Finance and HR Leads. Under the PET Lead supervision lies each of the planning, engineering, manufacturing and packaging departments. Departments that are directly involved in this study are marked in black in the below organization chart. This management structure is represented in the Issue management team that creates, maintains and activates the business continuity plan BCP in COVID-19.

It is worth notice that the marketing and sales activities are managed by the marketing company division outside the site premises. S\&OP meeting is a single point of contact between operations and commercial in regular meetings. The discussion includes demand, supply and forecasting issues. Meanwhile IT, R\&D services are globally managed through central functions that supports all sites. A research centers in UK and the USA are the places where new molecules are being developed, studied and tested prior to manufacturing. Common inputs to the pharmaceutical manufacturing process are raw materials; APIs and excipients, primary, secondary and/or tertiary packaging materials. Finally, the main output is the pharmaceutical product. 


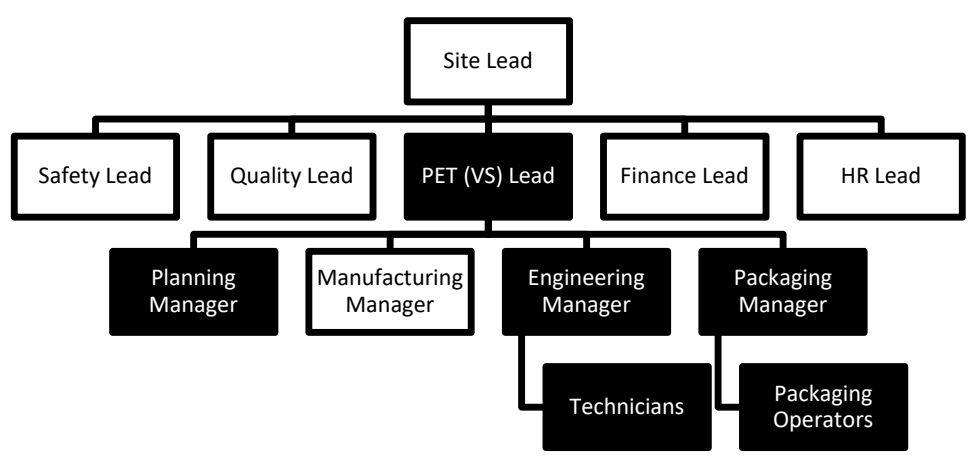

Figure 3. Organization Chart of Pharmaceutical Manufacturing Site

\subsection{External Environment}

At the macroeconomic level, Egyptian authorities have taken a series of precautionary actions to control spread of the virus. These restrictions included the nighttime curfew, complete lockdown for shopping malls, closing all leisure facilities and worship places i.e. mosques and churches. Then gradual relaxations were announced by $\mathrm{MOH}$ which adopted a three staged plan to return to normal ways of working.

According to International Monetary Fund report 'Policy responses to COVID-19' (IMF, 2020), it deemed inevitable that the pandemic will impact the Egyptian economy since the WHO stated the first case reporting in Egypt on the $14^{\text {th }}$ of February 2020. The graphs below present the number of cases reported on weekly basis in Egypt and the number of COVID-19 related absence in the company. Travel and tourism activities are declining, slowdown of local business activities due to the lock down and the relative global recession and reduction of exports due to low demand are among the reasons justifies the impact.

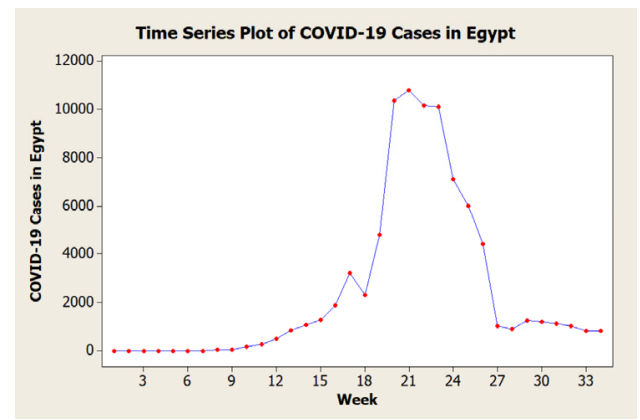

Figure 4. Weekly COVID-19 cases reported in Egypt (WHO, 2020).

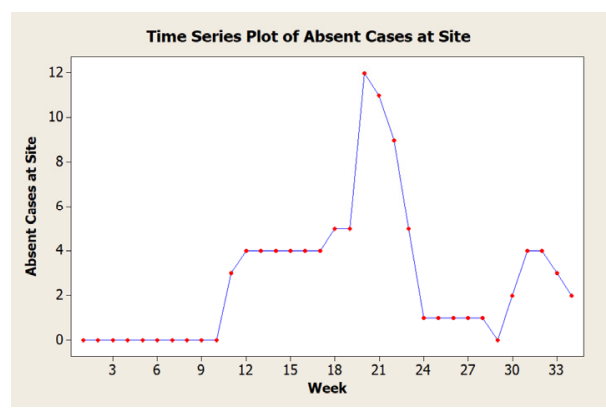

Figure 5: Weekly COVID-19 related absenteeism 
Socially, the announcement of the outbreak has created a panic among people. Fear was a driver for consumers who started building stocks of their essentials to avoid the expected stock outs of medications and goods. Sever increase in consumption was shown in media for food products, sanitizers and cleaning products. However, medications were not far from that impact. Similar practices were observed in pharmacies with the excessive purchases of chronic disease medicines. Some insurance companies allowed doubling the monthly prescribed quantity. COVID-19 related medication suffered severe demand variability particularly in the Egyptian market where prescription practice is not fully obeyed by.

Technology is helping manage the situation. Data analysis and statistical models are widely used to predict the infection and death rates and take proactive informed measures to control them. Telecommunication is one of the sectors flourished as it provided the sole mean of communication at time of lockdown and still providing solution to run businesses, schools and universities remotely.

There is no evidence that the climatic change will have an impact on the virus spread. Summer time has passed with limited numbers of new reported cases and deaths. However, winter is coming and the virus spread behavior cannot be anticipated.

\subsection{Internal Environment}

To demonstrate the Internal Environment of the pharmaceutical firms, Suppliers and customer are to be defined. Generally, the pharmaceutical industry in Egypt is mostly dependent on exportation of raw materials particularly APIs. Egypt imports approximately $90 \%$ of Chemical needs for pharmaceuticals. This is routed to the lack of local manufacturing capabilities. Germany, China, Switzerland, USA and India contributes to the largest proportion of raw and packaging materials importation according to (Egypt's Pharmaceutical Sector Following Bold Economic Reforms: Challenges and Opportunities, 2017). Domestic Suppliers for packaging components or chemicals are in turn depending on importation of starting materials.

Process customers can be classified as external and internal customers. External customers such as regulatory authorities, distributors and definitely the end user patients which lei beyond company control. However, internal customers are within the company's control. Quality, Warehouse and asset planners are among them. Employees are well trained and subject to intensive qualification protocols prior to work independently. Both companies under study are among the top paying companies in the sector. One of them is recognized as best place to work in Egypt. Production process starts with dispensing the materials for preparation, perform processing and formulation procedures to form homogenous product granules. Granules then compressed into tablets by tablet compression machines. Packaging is the last step in the in-site manufacturing process of pharmaceutical products when tablets are filled into formed blisters, sealed and packed. However, it is a critical unit-process that provides protection required for pharmaceutical products to withstand environmental factors during transportation, handling and storage.

\subsection{Stakeholders Reflections}

Upon discussion with stakeholders, it has been revealed that machine operators and technicians availability had a significant impact on production as a number of personnel were exempted from operation due to several factors. Either they were on sick leaves due to COVID-19 or they were suspect cases and dealt with self-isolation or even they were in close contact with a patient. Upon new safety instructions all the above mentioned cases were to be isolated on exceptional leave for at least 14 days. This impacted the availability of required to operate resources. And in cases they were replaced with contingent workers who are not at the same level of skills and required intensive training and qualification programs (Zaki, Ghalwash, \& Hossam, 2020).

Planning team members referred to the exceptional demand variability during the pandemic period as a major impact on efficiency. Flexibility and resilience are the only ways to survive such tough time, with excessive demand for some SKUs and sever underselling for others.

Management also referred to the $\mathrm{MOH}$ interference to control stock situation and secure the supply chain for any manipulation, fraud or falsification. That as well had impact on prioritization and setting production plans and schedules.

Management members referred to the need to intervene at certain time to secure supply. Such interventions are actions taken to overcome the excessive demand such as working on overtime and nightshifts. Additional operating costs were approved by top management to fulfil the high demand.

Major improvement projects were suspended for a while due to the travel ban policies adopted by some countries that prohibited technical experts from travel to the execution areas. Remote assistance alternatives were used to overcome some of the obstacles caused by this ban. 
Another factor that was mentioned in the discussion is the noticeable increase in employees' ownership and engagement during the crisis. Operators and managers all were working with a very high level of commitment. A lot of improvement initiatives and plan optimization came from the shop floor.

\subsection{Research Questions}

Does COVID-19 have significant moderating impact on the packing lines efficiency in Pharmaceutical firms?

\section{Literature review}

\subsection{OEE and the 6 Losses}

OEE is considered one of the metrics developed to enable organizations to monitor and benchmark there progress with easy and simple to understand metrics (Ravjibhai, 2017). Hence, OEE can not only be used as an indicator of the performance of equipment, but also it can be used to increase productivity of equipment as it clarifies the bottleneck in the production line (Omega \& Andika, 2017). Some previous studies included in this review agreed on the OEE calculation to be the multiplication of three elements namely; Availability, Performance and Quality rates, when Availability is the percentage of the actual running time to the total time the machine is available. Performance is defined by the percentage of actual production rate produced to the validated production rate. Quality rate is the percentage of the good output to the total quantity produced (Andersson \& Bellgran, 2011). Similar approach was taken by Hervian \& Soekardi (2013) and from both, the use of 6 big losses is suitable to determine the impact of COVID-19 on the OEE based on its impact on each of the 6 losses or their inputs.

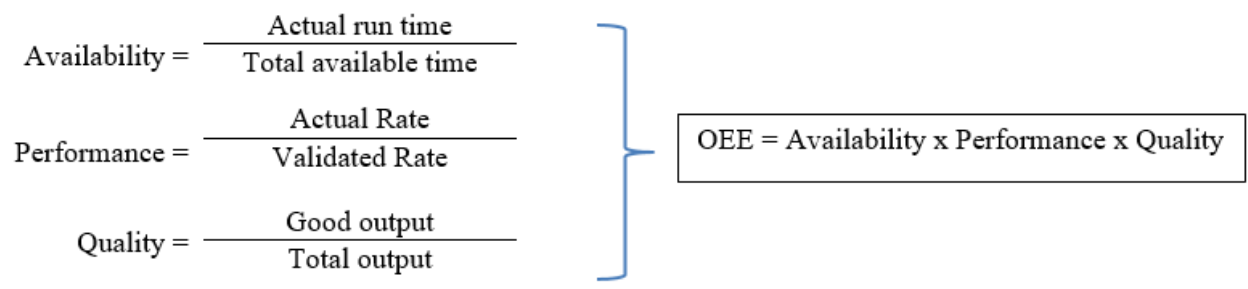

Figure 6. OEE calculation - own processing based on (Andersson, 2011)

OEE is a good indicator on production performance, it can be enhanced by reducing the six major losses namely; breakdown losses, setup and adjustment losses, idling and minor stoppage losses, reduced speed losses, quality defects and rework, startup losses (Sowmya \& Chetan, 2016).

Figure 5 illustrates a model for OEE using the six big losses of Total Productive Maintenance TPM and are classified into six major categories. Breakdown, setup and adjustment losses as direct indicators for availability losses. Defects and rework losses impacting quality rate. Meanwhile start-up and speed losses, and idling and minor stoppage losses represent major performance losses (Chikwendu, Chima, \& Edith, 2020). Accordingly OEE can be calculated by obtaining the product of performance efficiency of the process, the availability of equipment, and rate of quality products. OEE = Availability x Performance efficiency x Quality.

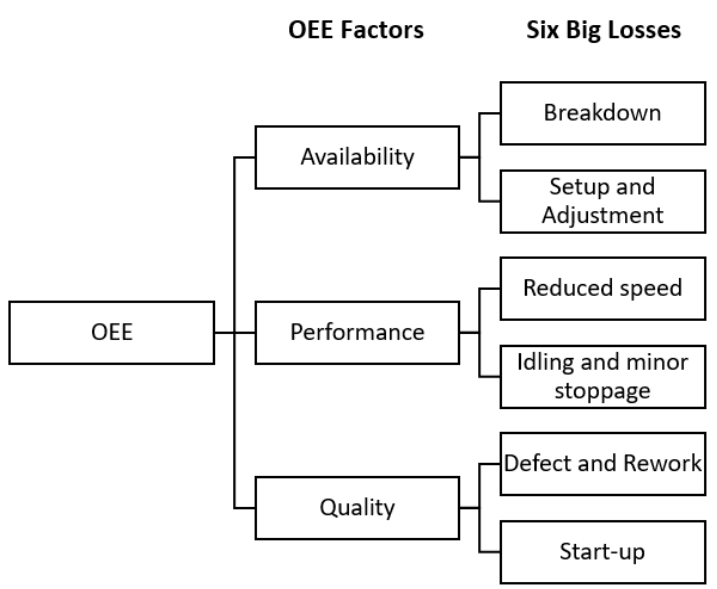

Figure 7. A model of overall equipment effectiveness (Chikwendu, Chima, \& Edith, 2020) 
It was concluded in their study that measuring OEE is confirmed to be an effective way of analyzing equipment performance in a pharmaceutical company, as it also takes into consideration the six big losses; Breakdown losses, setup and adjustment losses, idling and minor stoppages, reduced machine speed, defective products, and low yield.

According to Simoes Ramos da Silva (2016) the six major losses can be defined as follows;

Breakdowns are the defect or abnormal condition the prevent machine from functioning properly. Setup and Adjustments losses are the lost time in changeover; time between different batches. Idle / minor stops: short outages of the line when line cannot be continuously running for long time. Reduced Speed: working with speed less than the machine designed and validated rate. Defects and rework losses represents the cost incurred in the sorting, reuse or scrapping of the non-conforming packs. Finally, startup losses represent the reduction in production till the machine reaches steady state.

Ravjibhai (2017) elaborated more on the six losses and collected some examples of each of them. Tooling failures, unplanned maintenance, general breakdowns and equipment failure are typical examples for downtime losses. Changeover - the time between the last pack of a product and the first pack of the following batch - is a major contributor to availability losses. Nonetheless, material shortage and operator shortage also contribute to availability loss and consequently affecting OEE. Operator inefficiency is one of the stated examples affecting performance. Quality losses are mainly routed to rework and scrap.

A multifactorial study was done by Relkar and Nandurkar (2012) using a systematic approach to analyze factors impacting OEE by deliberately change some variables and monitor the impact on the OEE. Regression analysis proved significant impact of the three factors Availability, Performance and Quality on OEE. It proved Performance to have the most significant impact and recommends companies seeking OEE improvement to pay attention to performance parameters. Accordingly, if COVID-19 has impact on performance metrics it will have a significant impact on OEE.

Gurvich and Hussain (2020) defined the four critical elements of a comprehensive strategy for pharmaceutical manufacturing. First, innovative advanced manufacturing is a key success factor to fulfil the increasing demand. Pharmaceutical manufacturing is lacking the application of innovative advanced technological solutions as a result of seeking low labor cost approach rather than investing in developing technologies. Pharmacy colleges is in the lead now to seize the opportunity and improve their education and training programs. New prior knowledge and research and development is also considered an important element to enrich industry pipeline with new drugs and technologies.

\subsection{COVID-19 and Availability - Changeover and Batch Size}

In order to increase the OEE, companies must ensure active management involvement in addressing improvement opportunities and carrying them out, focusing on increasing production scheduling, equipment performance and reducing the quality issues before or during production (Winatie, Maharani, \& Rimawan, 2018). From the stakeholders' discussion in this review, changeover deemed to be a major problem impacting machine availability and accordingly OEE (Hossam, Personal communication, June 2020). Authors recommend Research and Development departments to improve changeover process to reduce time consumed in a non-value added activity. Scheduling can manipulate this impact by reducing number of Changeovers reaching the optimum product sequence - provided the high demand - will allow more efficient production scheduling that eliminates the waste of changeover. Moreover, high demand will also provide the opportunity to increase the batch size and increase run time which in turn will decrease idling time and availability losses.

Amio, Dey and Mahmud (2020) described some internal and external factors affecting machine availability and consequently OEE. Among the internal factors that lies beyond the company's controls are machine design and specifications and blister and pack properties. These factors are within the machine and cannot be easily changed.

\subsection{COVID-19 and Availability - Demand and Supply Change}

In a retrospective time-trend analysis by Romano (2020) of the sales of specific pharmaceutical products, an increase of medicines' demand during the pandemic was observed and even peaked after WHO declared COVID-19 a pandemic. Demand increase due to panic buying is considered one of the short term impact of COVID-19 (Ayati, Saiyarsarai, \& Nikfar, 2020). Demand is a key input to operations management which when increased allows for large batch size production. The increased batch size will decrease the number of changeovers and in turn increase machine availability a component of OEE calculations.

According to Mahase (2020) demand of dexamethasone has increased upon the declaration of a study results 
confirming the effectiveness of the drug to decrease death rate of COVID-19. Accordingly, production of dexamethasone must be rapidly increased to meet global demand. Further generalization to all COVID-19 related drugs listed by the WHO or in any governmental treatment protocol can be studied to be proven.

A risk was highlighted in a case study done in drugs manufacturing and distribution in Nigeria. The risk of the introduction of falsified medicines, counterfeited and fake drugs into the supply chain endangering millions of lives (Akande-Sholabi \& Adebisi, 2020). This may be a result from the increased demand during the pandemic. Less secured supply chains - in countries that had not applied Track and Trace system yet - are more vulnerable for counterfeit introduction than others with strong controlled drug distribution channels with traceability capabilities.

A group of Experts (2020) reported that upon industrial revolution 4.0 radical change to industrial work processes is expected due to the use of remote services and data-based problem solving approaches. In the era of Big Data and Virtual Reality tools, education, digital capabilities and analytics are to be the core focus of training investments in the human capital. The easier access to drug product via remote services required an agile and flexible supply chain including manufacturing process that should be as lean as possible in order to sustain business.

Intensive or extensive tactics of promotion are used by pharmaceutical companies to influence physicians prescribing their specific drug in order to increase revenue and gain market share (Bahlol \& Lagutkina, 2016). Pharmaceutical companies will seize every opportunity to benefit from the increased demand during the pandemic which will hold more need for efficiency and OEE improvement. This promotional push will also increase demand and indirectly impact OEE by increasing utilization and batch size.

During the pandemic, Supply chain and logistics interruption may lead to delayed drugs delivery and short supply (Ying, Qian, \& Kun, 2020). This is a result from the imbalance between the demand and supply. Demand is increased due to the practices carried out by pharmacists to manage the drug delivery during the crisis. For instance, a list of COVID-19 treatment drugs was developed as a part of drug supply schemes based on guidelines. Telephone and Online drug procurement were enabled easing access to medicines for patients.

A simulation model was used in a hypothetical study to analyze the impact of the outbreak on the supply of pharmaceutical products (Lozano-Diez, Marmolejo-Saucedo, \& Rodriguez-Aguilar, 2020). The model showed that several disruptions in the supply of medicine can be resulted from COVID-19. Authors recommended in their studies that in order to withstand any subsequent epidemiological outbreak, a resilient, reliable, fast and responsive drug supply chain and manufacturing should be built. Supply interruption of raw materials may lead to machine idling and utilization losses. However, utilization losses may not directly affect OEE, yet it can impact availability if material shortage was not proactively foreseen and material shortage discovered on the line.

The coronavirus outbreak severely affected the pharmaceutical supply chain and amplified the risk of overreliance on Chinese manufacturers for APIs and excipients since approximately $60 \%$ of the world's API were made in China. The shutdown of the majority of the drugs manufacturing facilities caused a shortage in the raw materials and subsequently a drug shortage on the market (Ozili \& Arun, 2020). Similar outcome is confirmed to be true for other markets in India which can be considered in this study due to the similarity in the reliance of Chinese suppliers (Chatterjee, 2020). The supply chain disruption has many dimensions; lockdown on many countries and restrictions on travel and cargo, shortage in supply due to unavailability of workers or tier 3 suppliers' - suppliers of suppliers - primary materials and increased demand that exceeded capacity of suppliers.

\subsection{COVID-19 and Availability - Workers Availability / Capability}

The impact of COVID-19 on workers in the food industry has been studied by Cho, Lee, and Winters (2020) who found a relation between the pandemic and the workers availability in the food manufacturing sector. This literature is found relevant to the research due to the similarities of food sector and pharmaceutical sector. Pharmaceutical products as well as food products are essential for human well-being. Hence, production and distribution of these products must be secured despite the difficulties faced in maintaining the health and productivity of workforce during the pandemic. The increased absenteeism of experienced industry-specific human capital will lead to productivity loss. New workers maybe hired as contingent business continuity response with less expected productivity and capability of trouble shooting. This in turn will impact machine performance (OEE) due to increased machine stops or machine availability due to unavailability of operator. Moreover, attention should be made to ensure safe working environment for workers. Increasing social 
distancing and providing protective equipment are among the measures that should be taken. In order to compensate these losses additional cost will be incurred to secure resources in terms of increased allowances.

\subsection{COVID-19 and Availability - Breakdowns}

Availability considers all the unplanned stops that causes the production to be down long enough normally more than $10 \mathrm{~min}$. Breakdowns and failure in machine components is one of the factors of machine down time (Amio, Dey, \& Mahmud, 2020). Machine downtime is defined as the time the machine suffers a component failure that prevent planned production. Uptime is the time the machine is running continuously and can be calculated as the time between two successive failures. The more the downtime is, the less the availability and OEE.

Based on the workers availability discussion and the breakdown definition, COVID-19 can have an impact on machine availability due to the long downtime routed to the absence of worker or inability of replacement worker to solve machine failure due to lack of experience.

\subsection{COVID-19 and Performance - Maintenance / Maintenance Competences}

Although long breakdowns - typically more than several minutes - are considered availability losses, minor stops are impacting machine performance. Generally, the most significant causes of outage are corrective maintenance and other minor stops. As Friedli and Goetzfried (2010) stated, "Reduced reliability of the machines contributes to the formation of in-process inventory and for the lack of adherence to the production scheduling" (as cited in Simoes Ramos da Silva, 2016). Maintenance programs should be in place in all manufacturing firms to prevent breakdown from occurrence. These programs should be built on a risk based approach and be data driven using historical performance and stops record of the equipment and considering supplier recommendations. These maintenances if not done on time or in a proper effective way, machine reliability may be doubted. In COVID-19 unavailability of skilled workers to do the maintenance or unavailability of spare parts may impact the quality the preventive maintenance program is executed which will result in multiple machine stoppages.

Three external factors impacting OEE defined by Amio, Dey and Mahmud (2020) that directly affect the machine availability are namely; maintenance personnel index, task severity index and daily maintenance index. The study concluded that the improvement of these factors is reflected in the machine availability level. It highlights the importance of machine maintenance and the manpower required to perform the maintenance. Also recommends further investigation of the spare parts availability to have a significant influence on machine performance.

Importance of training was concluded by authors. Both new machine operators and old experienced ones must be given retraining on how to maintain the machine (Winatie, Maharani, \& Rimawan, 2018).

\subsection{COVID-19 and Quality}

Drug products are expected to be of high quality to meet the safety, strength, and identity requirements. Pharmaceutical education is considered a critical element in the industry as each individual in the workforce should receive a proper training and education program (Gurvich \& Hussain, 2020).

Operators' flaws become result in unstable equipment operation, which in turn will increase process time and compromising the quality of the products (Simoes Ramos da Silva, 2016). Reduced quality output decreases the OEE and bears costs of rework and wasted materials.

Concerns over quality of products and the adequacy of regulatory oversight is raised due to the increased demand (Bown, 2020). This study is discussing impact on medical devices yet it is considered relevant as similar outcome can be seen in pharmaceutical firms. The increased demand may lead to attempts to shorten production time, manipulate process, or exceed speed limits which without proper validation and testing may jeopardize product quality.

Since pharmaceutical production is a regulated process and products are subject to quality control testing and inspection prior to disposition to the market, the impact of the above risk on quality is reflected in the upstream in the supply process affecting operation efficiency.

\subsection{Literature Review Conclusion}

Based on the above literature review, Overall Equipment Effectiveness (OEE) is deemed to be a valid metric to reflect changes in production efficiency. OEE is the product of machine Availability, Performance and Quality rates. 6 major losses are often used to breakdown the impact of any factor on OEE.

It can be concluded that the dependent variable OEE can be influenced by the moderating impact of COVID-19 
on the three components of its calculation; Availability, Performance and Quality. By having an impact (positive or negative) on the major factors contributing to the 6 big losses COVID-19 can alter OEE trends.

\section{Theoretical framework}

The research question - raised based on the above data - will form the below theoretical framework.

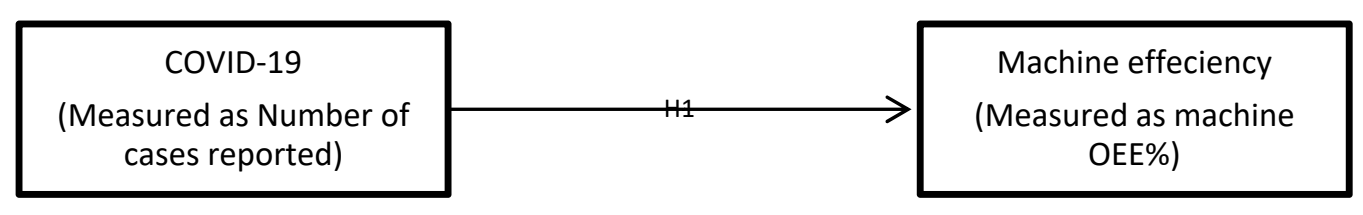

Figure 8. Theoretical Framework

The framework outlines the hypothesis that will be tested as follows:

$\mathrm{H}_{0}$ : there is no correlation between Covid-19 Cases and the OEE\%.

$\mathrm{H}_{1}$ : there is a correlation between Covid-19 Cases and the OEE\%.

\section{Methodology}

A retrospective study on one packing line of a pharmaceutical site in Egypt measures the correlation between COVID-19 and OEE. The data collected are the OEE components; availability and performance on weekly basis from January 2020 to October 2020, the number of COVID-19 related absence per week and the number of additional working hours per week for the same period of time. Quality is considered as 1 in the calculation and can be neglected from the calculation this is the normal practice at this site.

In order to study the moderating effect of COVID-19 and the OEE, Pearson correlation coefficient will be calculated between the number of cases reported for the week and the OEE for that week considering the additional overtime hours.

Correlation technique in Minitab software was used to calculate the relation between the variables.

Number of weeks observed $(\mathrm{N})$ is 34 . The weekly data is presented in the below graphs.

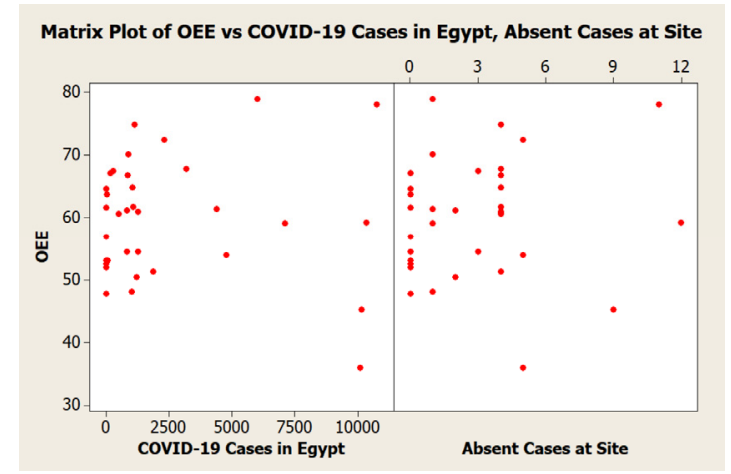

Figure 9. Matrix Scatterplot of OEE vs. COVID-19 Cases and Egypt and COVID-19 Related Absence at site 


\section{Data Analysis, Findings and Discussion}

The calculation results are tabulated in the below correlation matrix:

Table 1. Correlation matrix

\begin{tabular}{|c|c|c|c|c|c|c|}
\hline & & OEE & $\begin{array}{l}\text { COVID-19 } \\
\text { Cases in Egypt }\end{array}$ & $\begin{array}{l}\text { Absent Cases } \\
\text { at Site }\end{array}$ & $\begin{array}{l}\text { Overtime } \\
\text { (Hrs) }\end{array}$ & $\begin{array}{l}\text { Contingent } \\
\text { workers }\end{array}$ \\
\hline \multirow{3}{*}{ OEE } & Pearson Correlation & 1 & & & & \\
\hline & P-Value & & & & & \\
\hline & $\mathrm{N}$ & 34 & & & & \\
\hline \multirow{3}{*}{$\begin{array}{l}\text { COVID-19 Cases } \\
\text { in Egypt }\end{array}$} & Pearson Correlation & -0.052 & 1 & & & \\
\hline & P-Value & 0.772 & & & & \\
\hline & $\mathrm{N}$ & 34 & 34 & & & \\
\hline \multirow{3}{*}{$\begin{array}{l}\text { Absent Cases at } \\
\text { Site }\end{array}$} & Pearson Correlation & 0.115 & 0.741 & 1 & & \\
\hline & P-Value & 0.517 & 0.000 & & & \\
\hline & $\mathrm{N}$ & 34 & 34 & 34 & & \\
\hline \multirow{3}{*}{ Overtime (Hrs) } & Pearson Correlation & 0.014 & 0.294 & 0.407 & 1 & \\
\hline & P-Value & 0.938 & 0.091 & 0.017 & & \\
\hline & $\mathrm{N}$ & 34 & 34 & 34 & 34 & \\
\hline \multirow{3}{*}{$\begin{array}{l}\text { Contingent } \\
\text { workers }\end{array}$} & Pearson Correlation & 0.002 & 0.637 & 0.220 & 0.033 & 1 \\
\hline & P-Value & 0.990 & 0.000 & 0.211 & 0.854 & \\
\hline & $\mathrm{N}$ & 34 & 34 & 34 & 34 & 34 \\
\hline
\end{tabular}

The data analysis shows significantly strong evidence of the existence of positive correlation between Absenteeism and overtime hours worked to compensate the absent workers' availability losses. This is represented by the high Pearson correlation coefficient and the P-Value of $0.017(<0.05)$. Having a holistic view on the number of cases reported in the country, it triggers management intervention to secure products supply for patients. Hence, the positive correlation between the number of cases reported and the absence rate and consequently the need to hire contingent workers. This relations are significantly strong as P-Value of both is near zero.

Data also shows a positive correlation between OEE as an independent variable and the absent cases as independent variable. Yet the relatively high P-Value $(>0.05)$ fails to provide strong evidence to reject the null hypothesis.

The test has Cronbach's Alpha Reliability of 0.008. A poor reliability that is routed to the small number of items in the scale as only five items are being tested.

Health conditions of workers (operators and technicians) is a reason for absenteeism and unavailability of workers. Either because they are COVID-19 patients and developing symptoms or on self-isolation for being in contact with a positively tested case. This factor directly affects machine availability due to inability to operate without a worker (i.e. increased downtime) and indirectly affecting performance and quality as a result of hiring less-experienced inefficient worker that is unable to solve problems on time and cause multiple stoppages and defective units.

Although demand of COVID-19 related drugs is a predictable reaction to the pandemic and the high spread rate of the virus, demand of other pharmaceutical products also changed. Panic buy, increased remote services in drugs dispensing and retail practices and the increased promotion activities done by pharmaceutical companies to physicians are a contributing factors to the increased demand. Demand change consequently changes scheduling pattern by increasing the batch size to fulfil the needs. This result in better asset utilization and increased machine availability by decreasing the number of changeovers between different products and vise-versa for products with decreased demand. Change in availability will change the OEE.

This graph represent the percentage of actual sales to the forecasted sales volume. It shows demand variability and forecast inaccuracy as a result of the unpredictable pattern during the pandemic. 


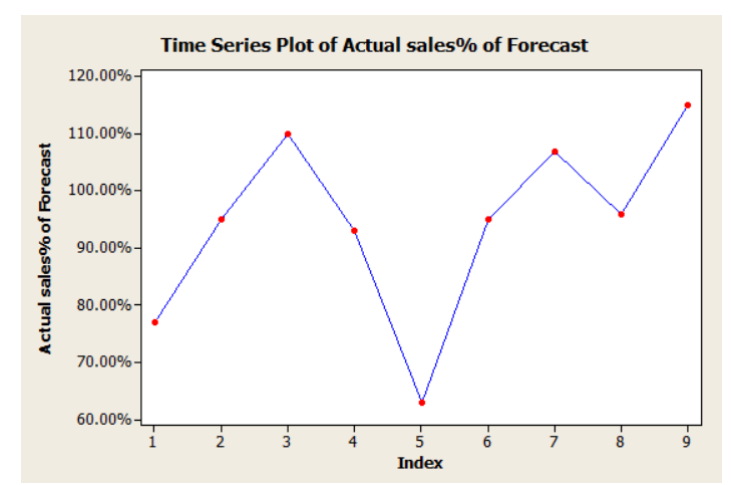

Figure 10. Monthly actual sales $\%$ of forecast

Supply interruption of materials may cause machine stop due to material shortage. In unsecured supply chains introduction of falsified materials or materials of lower quality causing minor stops impacting machine performance and may require sorting and rework resulting in lower quality rate.

Similarly, Spare parts supplier shortage and overreliance on sole supplier - e.g. China - can have impact on availability as machine failure may take longer till a specific part is sourced and installed. Moreover, this can jeopardize quality of the spare parts causing lots of minor stops and impacting performance and quality.

\section{Conclusion, Recommendations and Future Work}

\subsection{Conclusion}

The analysis concludes correlation between number of COVID-19 cases in Egypt and the absenteeism rate at the site which in turn positively correlated with number of overtime working hours to compensate the availability losses. This intervention diminishes the impact of COVID-19 on OEE.

\subsection{Recommendations}

Equipment owners, statisticians and analysts are to consider COVID-19 impact on OEE during studying the trends and statistical process chart of machine overall performance and parameters, to avoid misleading signals and set the proper improvement actions. Policy makers and business owners should prepare a business continuity plan (BCP) to be activated in similar pandemic situations. The plan should be concerned with workers safety and maintain the business running at the desired level of efficiency. They should take into consideration the factors tackled in this study.

To mitigate skill losses due to health conditions in such situation, skills flexibility level should be maintained at any point of time so that each skillful operator or technician can have one or more backup at the same level of knowledge and skills. Training programs and qualification protocols should be design considering skills availability and flexibility.

Maintain a minimum safety stock of materials and spare parts to compensate the impact of any shortage that may happen, as well avoid overreliance on sole supplier, keeping alternative suppliers to secure sourcing of materials, review supply chain design and try to build a more resilient and agile supply chain.

In order to maintain quality in tough situation more focus should be given for quality specifications and the importance of following standards to deliver quality products for which Training is the key.

\subsection{Future Research}

Further research is needed to validate the developed theoretical framework and the outcome from the problem definition and literature review. Deeper analysis to the impact of COVID-19 on the employees' performance, supply chain excellence is recommended.

\section{References}

Ahire, C. P., \& Relkar, A. S. (2012). Correlating Failure Mode Effect Analysis (FMEA) \& Overall Equipment Effectiveness (OEE). Procedia Engineering, 38, 3482-3486.

Akande-Sholabi, W., \& Adebisi, Y. A. (2020). The impact of COVID-19 pandemic on medicine security in Africa: Nigeria as a case study. Pan African Medical Journal. 
Amio, G. A. N., Dey, S., \& Mahmud, F. (2020). Examining Availability of a Packaging Unit: A Pharmaceutical Case. The International Conference on Industrial Engineering and Operations Management. Dubai, UAE.

Andersson, C., \& Bellgran, M. (2011). Combining Overall equipment Efficiency (OEE) and productivity measures as drivers for production improvements. Paper presented at Swedish Production Symposium, Lund, Sweden.

Annabi, M., Kebriaeezadeh, A., Shoshtari, S. N., \& Ghodsi, S. (2015). Priority Setting for Productivity Indices in Iranian Pharmaceutical Companies Introduction. Journal of Pharmacoeconomics and Pharmaceutical Management.

Ayati, N., Saiyarsarai, P., \& Nikfar, S. (2020). Short and long term impacts of COVID-19 on the pharmaceutical sector. DARU Journal of Pharmaceutical Sciences.

Bahlol, M. M., \& Lagutkina, T. P. (2016). Analysis of pharmaceutical companies' activities that are directed to Physicians in Egypt. Bulletin of Siberian Medicine.

Bicheno, J., \& Holweg, M. (2016). The Lean Toolbox (5th ed.). Buckingham, UK: PICSIE.

Bown, C. P. (2020). COVID-19: Demand spikes, export restrictions, and quality concerns imperil poor country access to medical supplies. Centre for Economic Policy Research. Retrieved from http://www.cepr.org

Chatterjee, P. (2020). Indian pharma threatened by COVID-19 shutdowns in China. The Lancet.

Chikwendu, O. C., Chima, A. S., \& Edith, M. C. (2020). The optimization of overall equipment effectiveness factors in a pharmaceutical company. Heliyon, 6, e03796.

Cho, S. J., Lee, J. Y., \& Winters, J. V. (2020, June 25). COVID-19 Employment Status Impacts on Food Sector Workers. Retrieved from IZA-Institute of Labor Economics: Retrieved from https://papers.ssrn.com/sol3/papers.cfm?abstract_id=3627034

N Gage Consulting. (2017). Egypt's Pharmaceutical Sector Following Bold Economic Reforms: Challenges and Opportunities. N Gage Consulting .

Elmahdawy, M., \& El-Khatib, A. (2011). Egypt Pharmaceutical Country Profile. Ministry of Health Egypt in collaboration with the World Health.

ElSafty, A. (2018). Business Research Methods. Egypt: Lecture Notes, Lecture One.

Elsafty, A. (2018). Lecture 2: Scientific Business Research Problem Definition [PowerPoint slides]. Maastricht School of Management, MBA Degree.

Elsafty, A. (2018). Lecture 2: Scientific Business Research Problem Definition [Lecture]. Maastricht School of Management, MBA Degree.

Elsafty, A. (2020). Dr Ashraf Elsafty Channel. Retrieved from Youtube: https:/www.youtube.com/watch?v=y-jDT2iOOhU\&list=PLKSWZdnzp8p3uFLLh2N8_d0W7ZmJDLMjW \&index $=42 \& \mathrm{t}=628 \mathrm{~s}$

Elsafty, A., \& AlNawaly, A. (2020). Role of Co-Working Spaces' Services in Entrepreneurs Growth in Upper Egypt, The Case of Step Co-Working Space. Business and Management Studies, 6(2), https://doi.org/10.11114/bms.v6i2.4899

Elsafty, A., Abadir, D., \& Shaarawy, A. (2020). How Does the Entrepreneurs' Financial, Human, Social and Psychological Capitals Impact Entrepreneur'S Success? Business and Management Studies, 6(3), 55-71. https://doi.org/10.11114/bms.v6i3.4980

Elsafty, A., Elbouseery, I., \& Shaarawy, A. (2020). Factors Affecting the Behavioral Intention to Use Standalone Electronic Personal Health Record Applications by Adults in Egypt. Business and Management Studies, 6(4), 14-36. https://doi.org/10.11114/bms.v6i4.5066

Elsafty, A., Elsayed, H., \& Shaaban, I. (2020), A Business Analysis Perspective for Engineering Education in Egypt. Journal of Education and Training Studies, 8(5). https://doi.org/10.11114/jets.v8i5.4721

Elsafty, A., Elsayed, H., \& Shaaban, I. (2020). Educating Engineering Students in Egypt: Recommendations for Improvement. International Journal of Higher Education. https://doi.org/10.5430/ijhe.v9n3p1

Elsafty, A., Elsayed, H., \& Shaaban, I. (2020). Journal of Education and Training Studies, 8(8). https://doi.org/10.11114/jets.v8i8.4901

Elsafty, A., \& Elzeftawy, A. (2021). The New Era of Digital Transformation and COVID-19 Effect on The 
Employment in Mobile Operators in Egypt. Business and Management Studies, 7(1), 1-21. http://dx.doi.org/10.11114/bms.v7i1.5087

Elsafty, A., \& Ragheb, M. (2020). Role of Human Resource Management towards Employees Retention during Covid-19 Pandemic. Business and Management Studies, 6(2). https://doi.org/10.11114/bms.v6i2.4899

Elsafty, A., \& Tahon, A. (2020). Exploring Impact of Corporate Social Responsibility on Organizational Performance, the Case of Turkish Islamic Banks. Business and Management Studies, 7(1), 1-21. http://dx.doi.org/10.11114/bms.v7i1.5087

Expert group, A. 6. (2020). Corona and the Consequences for Industry 4.0. Retrieved from https://ssrn.com/abstract=3617816

Field, A. (2009). Discovering Statistics using SPSS. Sage.

Gurvich, V. J., \& Hussain, A. S. (2020). In and Beyond COVID-19: US Academic Pharmaceutical Science and Engineering Community Must Engage to Meet Critical National Needs. AAPS PharmSciTech.

Hedman, R., Subramaniyan, M., \& Almström, P. (2016). Analysis of critical factors for automatic measurement of OEE. 49th CIRP Conference on Manufacturing Systems (CIRP-CMS 2016).

Hervian, M. S., \& Soekardi, C. (2013). Improving Productivity Based on Evaluation Score of Overall Equipment Effectiveness (OEE) Using DMAIC Approach on Blistering Machine. International Journal of Science and Research (IJSR).

IMF. (2020, September 15). Policy responses to COVID-19. Retrieved Septyember 152020 International Monatery Fund from https:/www.imf.org/en/Topics/imf-and-covid19/Policy-Responses-to-COVID-19\#E

Jha, R., \& Sharma, A. (2020). India's Pharmaceutical Industry: Global Supply Chain and Governance in the Post- COVID-19 World. ASARC Working Paper.

Kubiak, T. M., \& Benbow, D. W. (2015). Certified Six Sigma Black Belt Handbook (3rd ed.). American Society for Quality (ASQ).

Lozano-Diez, J. A., Marmolejo-Saucedo, J. A., \& Rodriguez-Aguilar, R. (2020). Designing a resilient supply chain: An approach to reduce drug shortages in epidemic outbreaks. EAI Endorsed Transactions on Pervasive Health and Technology.

Mahase, E. (2020). Covid-19: Demand for dexamethasone surges as RECOVERY trial publishes preprint. $B M J$ $369,2512$.

Nicola, M. E. (2020). The socio-economic implications of the coronavirus pandemic (COVID-19): A Review. International Journal of Surgery, 185-193.

Omega, D., \& Andika, A. (2017). Improving Overall Equipment Effectiveness Using CPM and MOST: A Case Study of an Indonesian Pharmaceutical Company. IOP Conf. Series: Earth and Environmental Science, https://doi.org/10.1088/1755-1315/101/1/012039

Ozili, P., \& Arun, T. (2020). Spillover of COVID-19: impact on the Global Economy. Retrieved Electronic copy from https://ssrn.com/abstract $=3562570$

Ravjibhai, P. C. (2017). Improvement in Overall Equipment Effectiveness (OEE) in Pharmaceutical company. G $\mathrm{H}$ Patel College of Engineering \& Technology.

Relkar, A. S., \& Nandurkar, K. N. (2012). Optimizing and analyzing Overall Equipment Effectiveness (OEE) Through Design of Experiments (DOE) . Procedia Engineering 38, 2973-2980.

Romano, S. E. (2020). Time-trend analysis of medicine sales and shortages during COVID-19 outbreak: Data from community pharmacies. Research in Social and Administrative Pharmacy, https://doi.org/10.1016/j.sapharm.2020.05.024

Simoes Ramos da Silva, B. M. (2016). Use of the indicator of overall effectiveness of equipment as a tool for continuous improvement: Case study applied to the pharmaceutical production. SISTEMAS \& GESTAO, 11(1), 49-60.

Sowmya, K., \& Chetan, N. (2016). A Review on Effective Utilization of Resources Using Overall Equipment Effectiveness by Reducing Six Big Losses. IJSRSET.

WHO. (2020, 10 08). Coronavirus. Retrieved October 08 2020, World Health Organization from https://www.who.int/health-topics/coronavirus\#tab=tab_1 
WHO. (2020, 11). Coronavirus Egypt Dashboard. Retrieved November 2020 World Health Organization: from https://covid19.who.int/region/emro/country/eg

Winatie, A., Maharani, B. P., \& Rimawan, E. (2018). Productivity Analysis to Increase Overall Equipment Effectiveness (OEE) by Implementing Total Productive Maintenance. International Journal of Innovative Science and Research Technology.

Ying, W., Qian, Y., \& Kun, Z. (2020). Drugs supply and pharmaceutical care management practices at a designated hospital during the COVID-19 epidemic. Research in Social and Administrative Pharmacy, https://doi.org/10.1016/j.sapharm.2020.04.001

Zaki, M., Ghalwash, M., \& Hossam, L. (2020, 09). Impact of COVID-19 on the pharmaceutical production efficiency. (M. Osman, Interviewer).

\section{Copyrights}

Copyright for this article is retained by the author(s), with first publication rights granted to the journal.

This is an open-access article distributed under the terms and conditions of the Creative Commons Attribution license (http://creativecommons.org/licenses/by/4.0/). 